\section{ECCOMAS}

Proceedia
COMPDYN 2021

$8^{\text {th }}$ ECCOMAS Thematic Conference on

Computational Methods in Structural Dynamics and Earthquake Engineering M. Papadrakakis, M. Fragiadakis (eds.) Streamed from Athens, Greece, 28 - 30 June 2021

\title{
OPTIMIZATION OF THE SLIP FORCE IN A NOVEL FRICTION-BASED CONNECTION FOR THE E-CLT TECHNOLOGY
}

\author{
A. Aloisio ${ }^{1}$, F. Boggian ${ }^{2}$, R. Tomasi ${ }^{3}$ \\ ${ }^{1}$ Department of Civil, Construction-Architectural and Environmental Engineering, Università degli \\ Studi dell’Aquila, L'Aquila, Italy, e-mail: angelo.aloisio1@univaq.it \\ ${ }^{2}$ Department of Civil, Environmental and Mechanical Engineering, University of Trento, Trento Italy, \\ Faculty of Science and Technology, Norwegian University of Life Sciences, Ås, Norway, e-mail: \\ francesco.boggian@unitn.it,francesco.boggian@nmbu.no \\ ${ }^{3}$ Faculty of Science and Technology, Norwegian University of Life Sciences, Ås, Norway, e-mail: \\ roberto.tomasi@nmbu.no
}

\begin{abstract}
The European Union has sponsored the development of a new friction dissipating system, for improving seismic behaviour of existing buildings. The proposed system consists of CLT-elements connected to the external beams of existing reinforced concrete building using steel profiles. Each of the steel profiles consists of two separate plates connected by a friction connection made by preloaded bolts in elongated holes. The authors carried out the experimental testing of the friction connection by estimating the corresponding hysteresis curve. A Duhem-like mechanical model, matching with the experimental results, simulates the cyclic response of the connection. The authors investigate the seismic performance of a structural archetype, a plane RC frame with CLT shear walls equipped with this sort of friction dampers. It is assessed the optimum preload condition to achieve an optimal seismic performance according to the Italian seismic scenario by the fragility assessments. A selected suite of earthquakes is the basis of Incremental Dynamic Analysis (IDA) of the structural archetype, without and with the friction device. The optimum preload of the dissipating systems descends by optimizing the structural performance: maximizing the dissipated energy by preventing damage to the CLT panel and the reinforced concrete frame.
\end{abstract}

Keywords: Seismic retrofitting, friction-based dissipation, Cross-Laminated Timber panels, Reinforced Concrete structures, Sustainability. 


\section{INTRODUCTION}

The vulnerability of the existing building entails developing non-invasive retrofitting approaches, based on passive devices [1, 2, 3].

The use of passive devices could be advantageous due to low-invasiveness and reduced installation time $[4,5]$, compared to more traditional seismic retrofitting strategies $[6,7,8]$.

Among them, friction-based dampers have shown great potential, compared to the most diffuse buckling restrained braces and fluid viscous dampers $[9,10]$. The performance of frictionbased systems is sensitive to dampers' location and the value of the slip forces. The first studies about friction dampers directed on experimental tests and technological development of the friction-based devices with the hysteresis loop's rectangular shape [11], as the Slotted Bolted Connection (SBC) discussed by $[12,13,14]$. Lately, several researchers proposed alternative friction dampers featured by nonrectangular hysteresis curves. Among the others, Clifton et al. [15] introduced the asymmetric sliding hinge joint (SHJ) for steel moment-resisting frames with a nonrectangular hysteresis.

A few investigations dealt with applications of friction devices on timber shear walls. Filiatrault et al. [16] proved the advantage in using friction sliders in timber sheathed shear walls. Loo et al. [17] confirmed the findings by [16]: they applied symmetric slip friction connections to replace the traditional nail plate hold-downs for timber Laminated-Veer-Lumber (LVL) walls. Hashemi et al. [18] extended the study by [17] to Cross-Laminated Timber (CLT) coupled walls and hybrid timber-steel core walls. Recently, Hashemi et al. [19] developed an innovative, resilient slip friction joint (RSFJ) characterized by a nonrectangular hysteresis shape.

The current research focuses on the e-CLT technology, developed on the ongoing multidis-

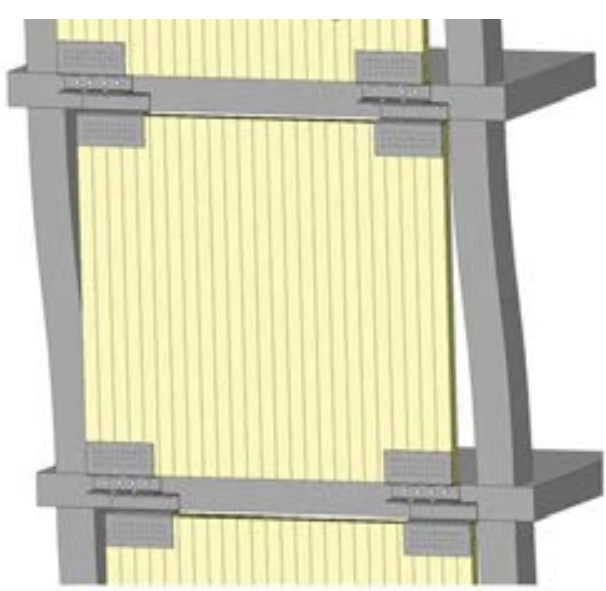

(a)

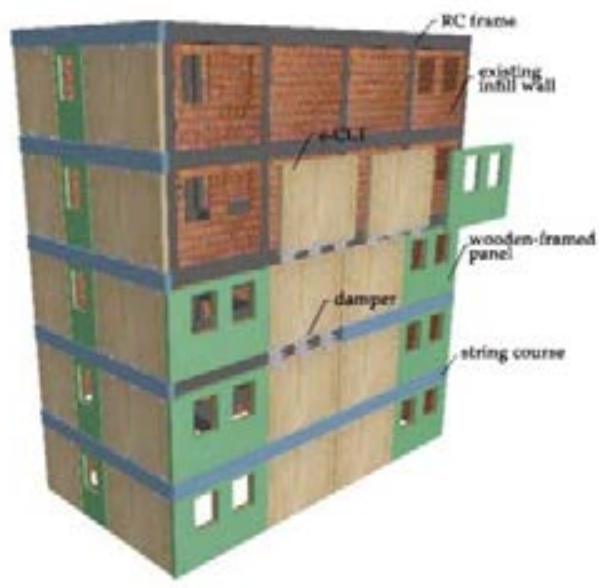

(b)

Figure 1: (a) Proposed friction energy dissipating system; (b) Illustration of a working application.

ciplinary Horizon 2020 research project e-SAFE (Energy and Seismic AFfordable rEnovation solutions): an application of Asymmetric Friction Connection (AFC) dampers and CLT panels on existing reinforced concrete structures for seismic retrofitting purposes.

The AFC is an arrangement of five plates, three steel plates and two thinner plates, named shims, assembled using high strength bolts. The AFC were studied by [15]. Primary attempts used brass shims based on the energy dissipation mechanism proposed by [14] for slotted bolted connections. Succeeding studies carried out by [20] extended the SHJ idea to mild steel and aluminium shims. Fresh studies carried out by [21] introduced bisalloy grades 80 and 400 shims. 


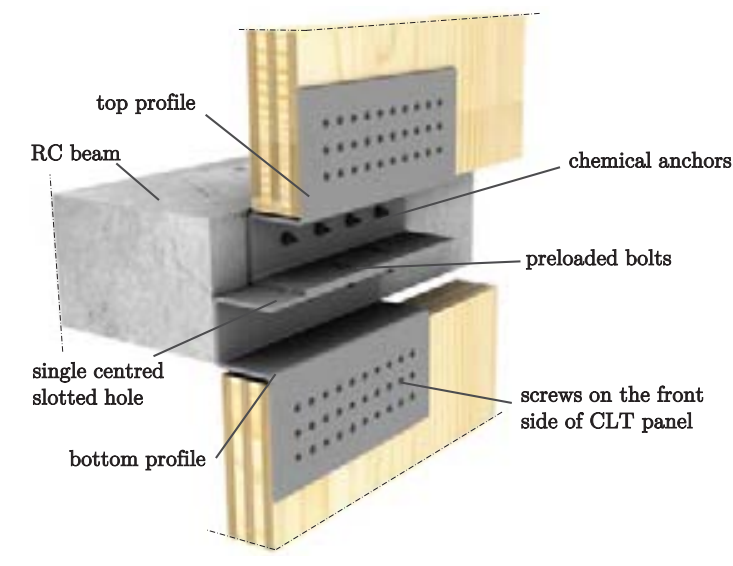

(a)

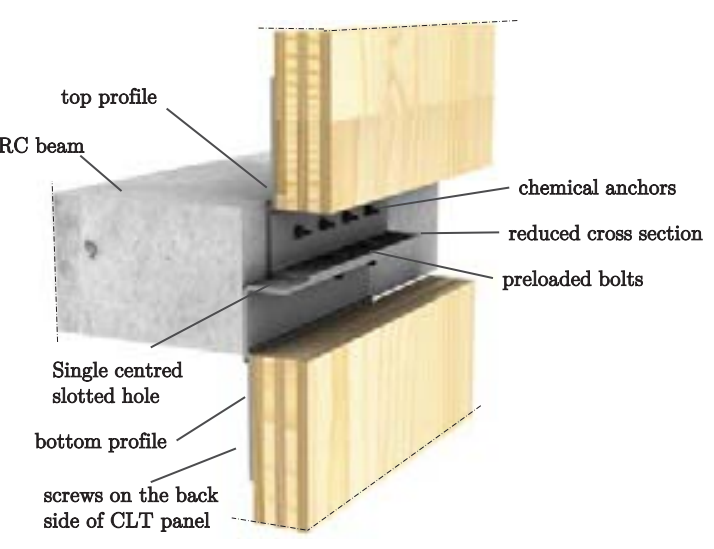

(b)

Figure 2: (a) Possible profile design with front mounted CLT panel; (b) Possible profile design with back mounted CLT panel.

The e-CLT technology consists of the external application of prefabricated Cross-Laminated Timber (CLT) $[22,23,24]$ structural panels by connecting them to the RC beams through AFC, see Fig. 1 and 2. If moderate earthquakes occur, the dampers rigidly connect the CLT panels to the RC structure, by enhancing the lateral stiffness and strength. During strong ground motions, the friction dampers activate with possible significant energy dissipation. The e-CLT system aims at reducing the storey drift demand and the damage to nonstructural and structural components. The presented retrofitting intervention may combine the e-CLT technology with nonstructural pre-assembled panels made of wooden frames and provided with high-performing windows to replace the existing ones. Not secondarily, structural and nonstructural panels integrate bio-based insulation materials and the desired finishing layer to improve the energy performance and the architectural image of the renovated building [25].

The e-CLT technology comprises the installation of AFC, whose response is mostly driven by Columbian forces. The damper consists of a contacting friction interface clamped by pretension high strength bolts: the friction interface sliding guarantees energy dissipation. The device has two cold-bent steel profiles that connect the CLT panels of two consecutive storeys with the existing interposed $\mathrm{RC}$ beam. The upper profile is connected to the $\mathrm{RC}$ beam by anchor bolts. The bottom profile is provided with slotted holes and is connected to the upper one by pre-tensioned high strength bolts. Standard timber screws connect both the upper and bottom profile to the CLT panels. The authors present the experimental cyclic response of the considered AFC by addressing the slip force's role for its optimum design.

To the authors' knowledge, a few studies focused on the optimum design of friction-based dampers. The most recent researches examine the optimum design of friction-based dampers installed on structural archetypes through nonlinear dynamic analysis driven by optimization algorithms [26].

So far the most significant achievements about the optimum design of friction-based dampers are:

- Optimum distribution of the friction device and optimum selection of the slip force value can lead to a more than $50 \%$ reduction of the inter-storey drift in RC frames. Additionally, a nonuniform distribution of the total slip force along the building's height can further reduce the inter-storey drift $[27,28]$. 
- The optimum slip load values are more affected by the amplitude and frequency of the input earthquakes (e.g. peak ground acceleration) rather than the characteristics of the structure [16].

- [29] derived an empirical equation which predicts the optimum slip load:

$$
R=1.12 e^{-0.11 n}
$$

where $R$ is the ratio between the average of the slip loads with uniform cumulative distribution and the average shear strengths of the storeys, $n$ is the number of storeys.

The mentioned studies, focused on optimizing slip-forces in friction dampers, required extensive parametric studies, which involved modelling a large variety of structural archetypes. However, the analyses' main drawback stood in the adoption of simplified constitutive models for concrete and the dampers and the modelling of the frames without the infill. The use of an elementary Coulomb-like friction model may be inadequate due to the possible higher slip force during the first cycles. The stability of the hysteresis loop and the magnitude of the friction forces developed by AFC specimens are directly related to the shim material hardness [30]. The presence of the masonry infill affects the seismic performance of RC frames significantly by increasing both the stiffness and resistance, as well as the ductility and pinching phenomena [31].

This paper investigates the performance of the e-CLT technology on an RC frame with masonry infill, which is the primary unit of many existing RC buildings. The main novelties of the research are:

- Discussion of the experimental cyclic response of a novel AFC, included in the e-CLT technology, and presentation of an enhanced Coulomb-like model.

- Investigation of the seismic response of an elementary RC frame equipped with the AFC using the Atan model calibrated on the experimental cyclic response of an RC frame with clay infill. Estimation of the optimum slip-force in the considered system, which yields the minimum displacement drift.

- Comparison between the optimization results with existing empirical formulations useful for preliminary design.

The paper has the following organization. The second section formulates the optimization problem, while the third presents and discusses the experimental tests on the friction-based dampers. The fourth section addresses the modelling choices and the calibration of the hysteresis models for simulating the RC frame and the friction damper. The fifth section discusses the first results obtained from the coupled system, while the sixth section deals with the optimization problem's solution. The last section compares the obtained results to the existing formulations by proposing alternative design approaches.

\section{ACTIVATION CONDITION}

The preliminary design of friction-based dampers may descend from the definition of their activation condition. The activation identifies the phase when the inertial forces win the connection's slip resistance, and the device starts dissipating energy.

The activation condition definition is crucial: a precocious activation may lead to a non-optimum 
exploit of the structure's elastic energy. A late activation determines the safety margin's erosion: the damper may start dissipating when the system has already suffered extensive and critical damage. Therefore, the activation phase must occur just in time to yield the maximum benefits to the structure.

Likely, the activation is not contemporary between all devices, since the structural deformation is not uniform within the structure. Therefore, the activation condition's optimum design is the most crucial task in designing a retrofitting intervention based on friction dampers. The practitioner must design both the slip force and the distribution of the dampers inside the structure.

Let us consider an elementary structural archetype, a plane frame, representing the primary structural unit in an RC frame building. The dampers' activation at the i-th storey occurs when the inter-storey drift exceeds a given threshold.

The authors will focus on estimating the slip force associated with a structural archetype's optimum seismic performance and will neglect to determine the dampers' optimum distribution, which can be the object of future investigations.

Why is the design of the slip resistance a minimum problem? Let us consider the maximum inter-story drift, which is an acknowledged indicator of the damage level in both structural and non-structural elements of RC structures [32]. The displacement drift depends on multiple factors. The authors will consider the sole slip resistance of the damper:

$$
d_{\max }=f\left(F_{s, R}, \boldsymbol{x}\right)
$$

where $d_{\max }$ denotes the maximum displacement demand, $F_{s, R}$ is the damper slip resistance and $\boldsymbol{x}$ collects additional variables affecting the maximum drift demand (structural stiffness, e.g.). The following paragraphs explain the presumed evolution of the maximum displacement demand as a function of the slip resistance, qualitatively illustrated in Fig.3.

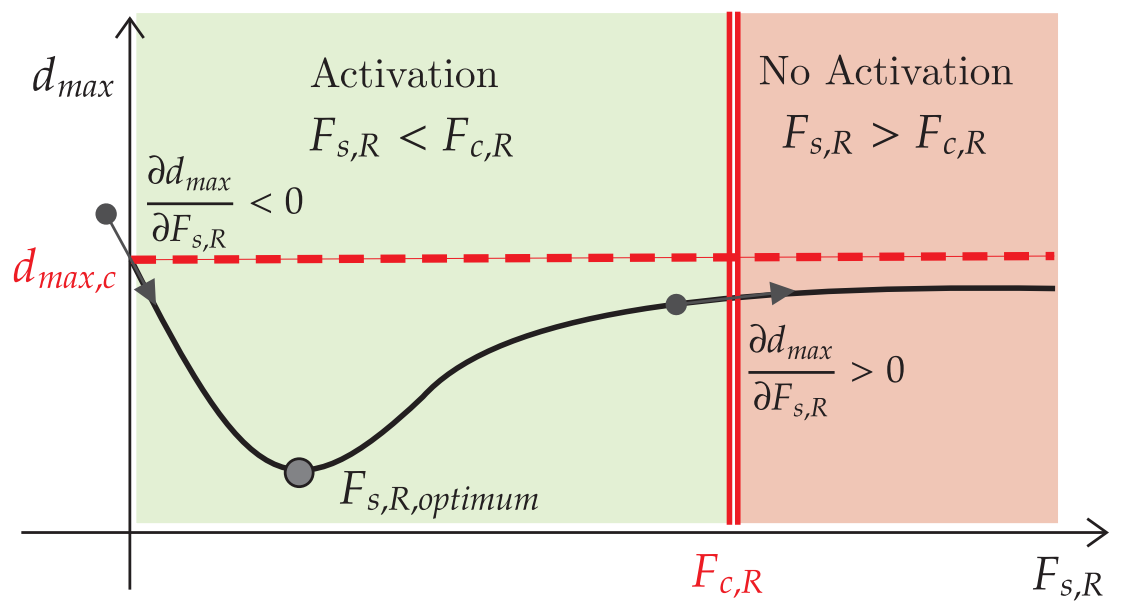

Figure 3: Qualitative illustration of the trend of the maximum displacement $d_{\text {maximum }}$ as a function of the slip resistance of the AFC.

The displacement drift is related to the dissipated energy during the seismic excitation. If the damper's slip resistance tends to zero, the structure behaves as if no damper is installed.

$$
\lim _{F_{s, R} \rightarrow 0} d_{\max }=d_{\max , c}
$$


where $d_{\max }$ is the maximum displacement demand, and $d_{\max , c}$ is the maximum displacement demand of the RC structure without dampers. If the slip resistance tends to infinity (Eq.4), the damper does not activate, and the structure behaves as if no damper is installed and the CLT panel behaves as an additional stiffening element reducing the maximum displacement demand: the slip resistance would be higher than the shear resistance of the RC structure, expressed by a double vertical line in Fig.3.

$$
\lim _{F_{s, R} \rightarrow \infty} d_{\max }=d_{\max , c}-d_{C L T}
$$

where $d_{C L T}$ is a contribution which lowers the displacement demand due to the additional stiffness of the CLT panel. If the slip resistance increases from the zero value, see Fig.3, the dissipated energy increases. The damper activates when there are low inertial forces. Still, the friction-based device must endure significant displacement to obtain a meaningful energy dissipation. However, the drift should reduce, and the following derivative would be negative:

$$
\lim _{F_{s, R} \rightarrow 0} \frac{\partial d_{\max }}{\partial F_{s, R}}<0
$$

If the slip force is lower than the shear resistance of the structure, the damping device can activate, green region in Fig.3. However, if the slip resistance reduces from the value corresponding to the structure's shear resistance (red area in Fig.3), the expected drift should reduce. The damper may start dissipating when the system did not attain the maximum displacement capacity, thus increasing the dissipated energy and possibly lowering the drift demand. The AFC has larger displacement margin for dissipation. Therefore, the following derivative would be positive:

$$
\lim _{F_{s, R} \rightarrow F_{c, R}} \frac{\partial d_{\max }}{\partial F_{s, R}}>0
$$

where $F_{c, R}$ is the shear resistance of the RC frame. The design of the slip force resembles a minimum problem. Likely, there is a force value which may minimize the drift demand during seismic excitation. The mathematical problem cannot have a closed-form formulation. The optimum performance depends on the expected seismic scenario. Therefore, the authors followed an a posteriori approach, conventional in earthquake engineering. They select a set of earthquakes, matching a given design spectrum. Then, they estimated the nonlinear dynamic response of a specific structural archetype by varying the slip resistance in a given range-the minimum of these values obtained from the considered list of earthquakes identifies the optimum solution.

$$
F_{s, R, \text { optimum }}=\underset{F_{R, s}}{\arg \min } d_{\max }\left(F_{R, s}, a_{g}\right)
$$

where $a_{g}$ represents a seismic scenario. The paper aims to solve the minimum problem in a specific structural configuration, representing the anatomical unit of the e-CLT technology.

\section{Experimental tests}

The authors investigated the cyclic behaviour of the AFC devised for e-CLT technology. The considered setup focuses on the friction damper and does not include CLT elements. The experimental setup consists of a rigid steel frame, namely the columns have a $12.5 \mathrm{~mm}$ thickness and $100 \times 200 \mathrm{~mm}$ rectangular section, the bottom profile of the specimen is attached to the right 
column, while the top profile is in the central part of the frame and is free to slide, being connected to the actuator of the press. An additional steel cap plate and two aluminium shim layers were inserted between the profiles, to obtain an asymmetrical friction connection. The goal of
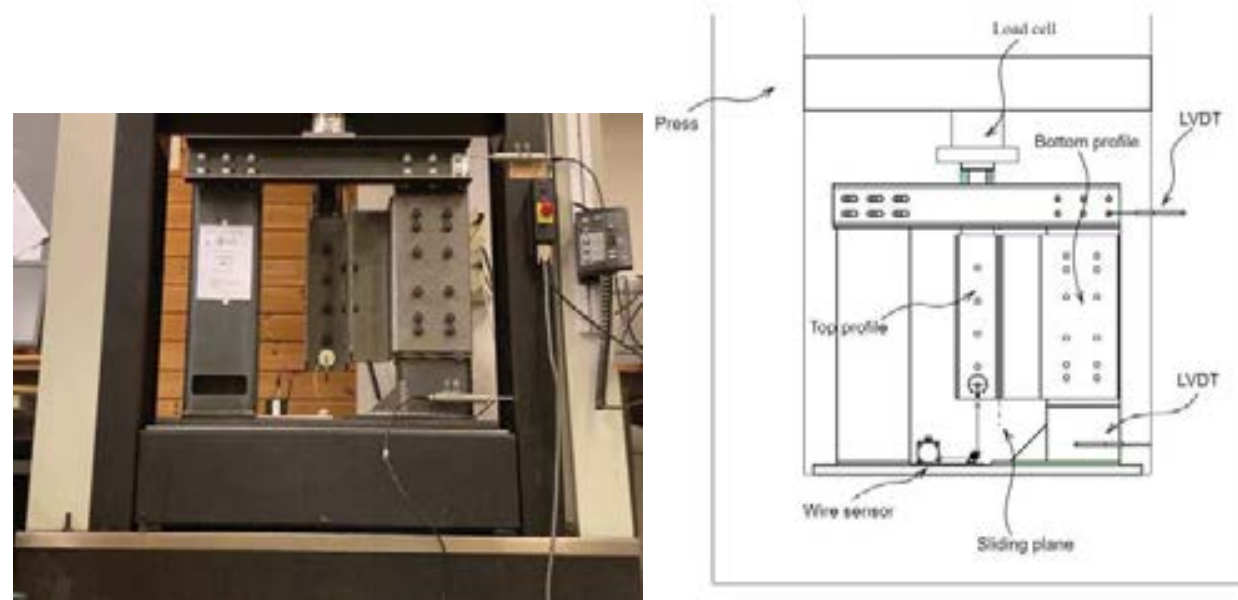

(a)

Figure 4: (a) Setup with all measuring instruments mounted; (c) illustration of the setup

the friction connection in the current setup is to have a $30 \mathrm{kN}$ sliding force, this threshold originates from the working limit of the press machine and previous FEM models [33]. The preload force in the bolt was set to $F_{P, c}=36 \mathrm{kN}$, which resulted in an experimental slip resistance $F_{s, R}=29.57 \mathrm{kN}$, calculated as [17]. The experimental friction coefficient is calculated as:

$$
\mu=\frac{F_{s, R}}{n_{s} n b F_{p, C}}=\frac{29.57}{2 \cdot 2 \cdot 36}=0.21
$$

where $F_{s, R}$ is the experimental slip resistance, $n_{s}=2$ is the number of shear surfaces, $n_{b}=2$ is the number of the preloaded bolts and $F_{P, c}$ is the preload force in the bolts. Interestingly, the

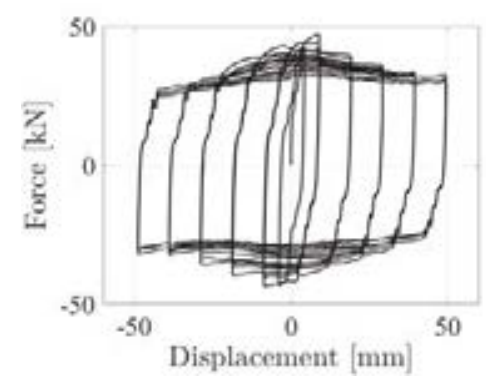

(a)

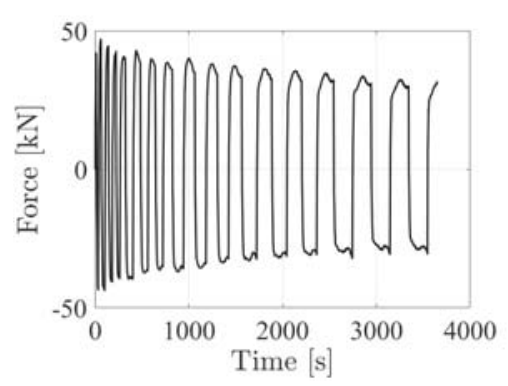

(b)

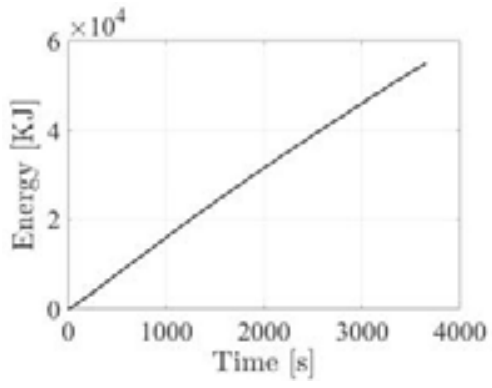

(c)

Figure 5: (a)Experimental hysteresis loop; (b) Force-Time function; (c) Dissipated Energy-time function.

estimation of resistant slip force is not unmistakable. The hysteresis loop does not display an expected rectangular shape. There is a significant increment of the slip resistance in the first few cycles at lower displacements, while it stabilizes at higher displacement to an almost constant value equal to $30 \mathrm{kN}$, as seen in Fig.5. This effect is not negligible, since there is an approximate $56 \%$ increment of the peak to the stable value at higher deformations. The modelling of this 
phenomenon is mandatory to achieve a reliable prediction of the performance of this system. This aspect is in full accordance with the experimental tests reported by [30]. Specifically, the adoption of an aluminium plate, characterised by low hardness, causes moderately stable loops. The friction coefficient corresponding to the peak force value is, in fact:

$$
\mu=\frac{F_{\text {peak }}}{n_{s} n b F_{p, C}}=\frac{47.03}{2 \cdot 2 \cdot 36}=0.33
$$

This value is in accordance with the findings by [30], who, in the case of aluminium shims, obtained a static friction coefficient of 0.34 and a dynamic of 0.21 .

\section{MODELLING OF THE COUPLED SYSTEM: RC FRAME, CLT PANEL AND AFC CONNECTION}

The authors modelled the hysteretic response of the RC frame in Fig.6(a). Fig.6(b) shows the experimental cyclic response by increasing the displacement at each cycle up to a drift of 2.5 $\%$. The authors reproduced the hysteretic response in Fig.6(b) using the Atan model, presented

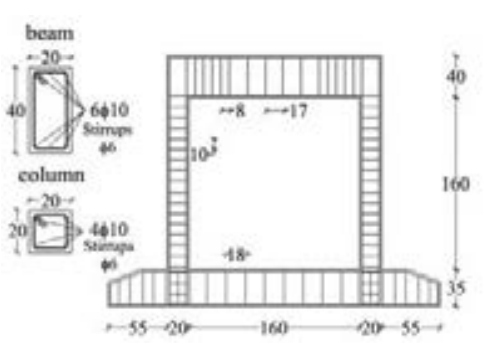

(a)

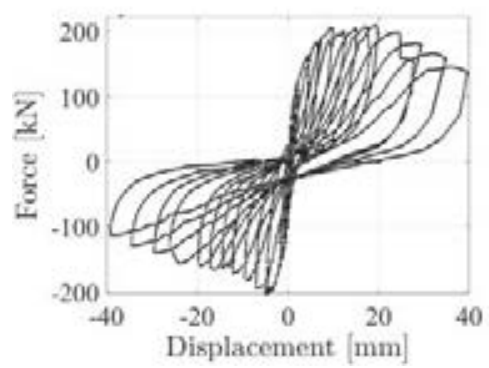

(b)

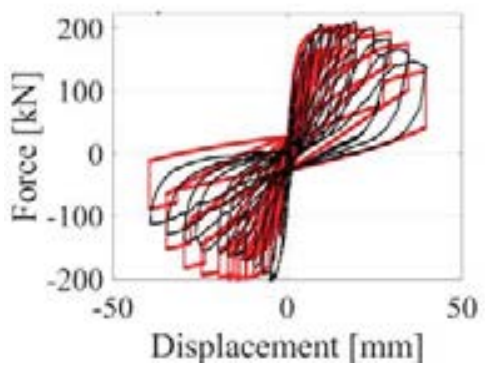

(c)

Figure 6: (a) RC frame subject to cyclic loading after [31]; (b) Experimental hysteresis loop; (c) Comparison with the Atan model.

by [34], which suits the simulation of mechanical systems with pinching, and both strength and stiffness degradation. It is a hysteresis model based on the arctangent function characterized by the following piece-wise definition:

$$
\begin{array}{lll}
1-a_{1} \arctan \left(b_{1} x-\left|c_{1}\right|\right) & \text { if } & \{\dot{x}>0, x>0,|x|>q \max (|x(t)|) \forall t \in[0, t)\} \\
2-a_{2} \arctan \left(b_{2} x-\left|c_{2}\right|\right) & \text { if } & \{\dot{x}<0, x>0\} \\
3-a_{3} \arctan \left(b_{3} x+\left|c_{3}\right|\right) & \text { if } & \{\dot{x}<0, x<0\} \\
4-a_{4} \arctan \left(b_{4} x-\left|c_{4}\right|\right) & \text { if } & \{\dot{x}>0, x>0,|x|<q \max (|x(t)|) \forall t \in[0, t)\} \\
5-a_{5} \arctan \left(b_{5} x+\left|c_{5}\right|\right) & \text { if } & \{\dot{x}>0, x<0,|x| \leq q \max (|x(t)|) \forall t \in[0, t)\} \\
6-a_{6} \arctan \left(b_{6} x+\left|c_{6}\right|\right) & \text { if } & \{\dot{x}>0, x<0,|x| \leq q \max (|x(t)|) \forall t \in[0, t)\}
\end{array}
$$

where the six conditional statements identify the transition between the different parts of the hysteresis. A set of three parameters define the arctangent function in each section of the loop: $a_{i}$ characterise the amplitude of the force, $b_{i}$ the $\mathrm{x}$ axis resolution and $c_{i}$ the residual displacement. The subscript $i$ varies between 1 and 6 . The strength and stiffness degradation descend from the use of an exponential function, like in $[35,36]$. The exponential function expresses the force and stiffness degradation as a function of the dissipated hysteretic energy $(\epsilon)$. The energy-dependent definition of $a_{i}$ and $b_{i}$ is:

$$
a_{i}(\epsilon)=e^{\left(-\xi_{a_{i}} \epsilon\right)} a_{0}
$$




$$
b_{i}(\epsilon)=e^{\left(-\xi_{b_{i}} \epsilon\right)} b_{0, i}
$$

where $\xi_{a_{i}}$ and $\xi_{b_{i}}$ are properly calibrated to the degradation of the strength and stiffness respectively. The parameters are $a_{0}=\frac{2 F_{u}}{\pi}$ and $b_{0, i}=\frac{k_{0}, i}{a_{0}}$, where $k_{0, i}$ is the tangent stiffness, and $F_{u}$ is the ultimate resistance.

Fig.6(c) displays the superposition between the experimental cyclic response of the RC frame and the simulated one using the Atan model with the parameters in Tab.1. The model satis-

Table 1: Parameters of the Atan model for the simulation of the cyclic response of the RC frame in Fig.6.

\begin{tabular}{cc}
\hline Parameter & Value \\
\hline$a_{0}$ & 140.12 \\
$b_{0,1}, b_{0,4}$ & 0.71 \\
$b_{0,2}, b_{0,3}$ & 0.32 \\
$b_{0,5}, b_{0,6}$ & 0.25 \\
$c_{1-6}$ & 0.20 \\
$\xi_{a i}, \xi_{b i}$ & 0.00005 \\
$q$ & 0.80 \\
\hline
\end{tabular}

factorily follows the experimental data by exhibiting the expected degradation behaviour. The model's significant stability under dynamic excitation endorsed this model's adoption: it was explicitly conceived to enhance the stability of hysteresis models with pinching, which present several convergence issues due to the stiffness boost in the pinched branches.

Columbian friction mainly drives the cyclic response of the AFC. Therefore, the authors adopted the following definition of the slip force:

$$
F_{s}(\epsilon)=\mu(\epsilon) F_{p, C} \operatorname{sign}(\dot{x})
$$

where $F_{s}(\epsilon)$ is the slip force, $F_{p, C}$ is the absolute value of the preload force, $\dot{x}$ the velocity of deformation, $\epsilon$ is the dissipated hysteretic energy. The definition of the friction coefficient is:

$$
\mu(\epsilon)=\mu_{0}[\exp (-\xi \epsilon(i))+1]
$$

where the $\mu_{0}$ and $\xi$ from an ordinary least squares optimization are 0.33 and 0.00005 respectively. The authors noticed that an exponential function closely follows the strength evolution

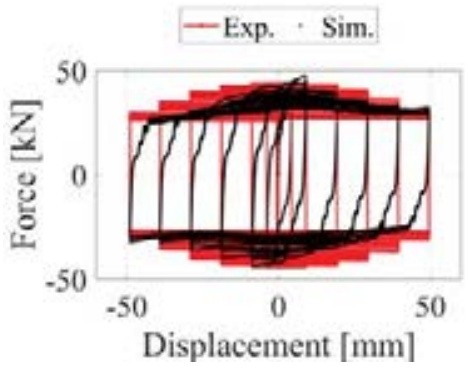

(a)

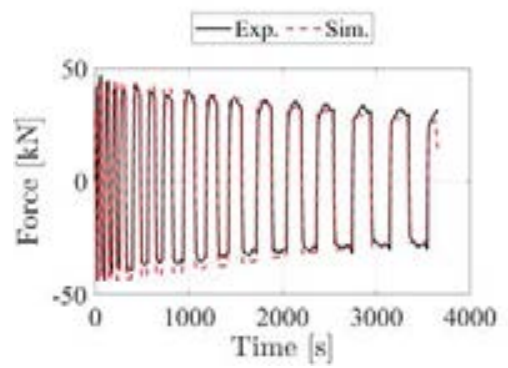

(b)

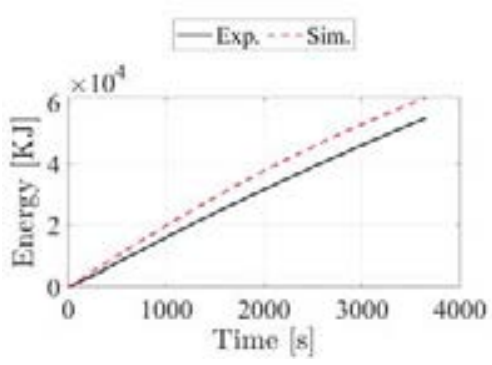

(c)

Figure 7: Comparison between the experimental data and the Coulomb-like friction model: (a) Hysteresis loop; (b) Force-Time function; (c) Dissipated Energy-time function. 
of the AFC. Fig.7 presents the comparison between the experimental data and the Coulomb-like friction model. The model seizes the experimental response, but it exhibits an energy dissipation higher than expected due to the loop's non-rectangular shape due to the corner chirping effect. The authors neglect this phenomenon in the current investigation due to its limited influence on the dissipated hysteretic energy.

\subsection{Modeling the coupled system}

The assemblage of the RC frame with masonry infill, a CLT wall panel and the AFC represents the structural unit of the e-CLT technology. In the considered system, the CLT panel's in-plane resistance must be higher than the slip resistance of the AFC. The CLT panel increases the RC frame's strength and stiffness, but the sole AFC provides the extra dissipation capacity. Accordingly, a linear elastic behaviour of the CLT is assumed for the modelling of the panel. In the current case, the structural unit consists of the RC frame equipped with a $90 \mathrm{~mm}$ thick CLT panel, circumscribed by the frame. Likely, the CLT panel behaves like a clamped-clamped beam. Therefore, the lateral stiffness is:

$$
k_{C L T}=\frac{1}{\frac{h^{3}}{12 E I}+\frac{1.2 h}{G A}}
$$

where $k_{C L T}$ is the lateral stiffness, $h$ the panel's height, $E$ the longitudinal elastic modulus, $I$ the cross-section inertia, $G$ the shear modulus, $A$ the cross-section area. The authors adopted the following parameters $E=11600 \mathrm{MPa}$ and $G=450 \mathrm{MPa}$. The assemblage's lateral resistance, $F_{T}$, is the summation of the three contributes, conditional of the exceeding of the slip resistance: the resistance of the RC frame $F_{c}$, the slip resistance of the AFC $F_{s}$ and the CLT panel contribute $F_{C L T}$.

$$
F_{T}(x, \dot{x}, \max (|x(t)|), t, \epsilon)=F_{c}(x, \dot{x}, \max (|x(t)|), t, \epsilon)+F_{\mathrm{CLT}}(x) \text { if } F_{T} \leq F_{s}
$$

$$
F_{T}(x, \dot{x}, \max (|x(t)|), t, \epsilon)=F_{c}(x, \dot{x}, \max (|x(t)|), t, \epsilon)+F_{\mathrm{CLT}}(x)+F_{s}(\dot{x}, \epsilon) \text { if } F_{T}>F_{s}
$$

where $x$ is the top displacement of the frame, $F_{c}$ is described by the Atan model, $F_{s}$ by Eqs.(13)(14), and $F_{C L T}=k_{C L T} x$. Likely, the combination of Eqs.(16)-(17) would simulate the lateral response of the structural unit obtained by assembling the RC frame, the CLT panel and the AFC connection.

\section{SEISMIC PERFORMANCE OF THE STRUCTURAL ARRANGEMENT}

The inelastic restoring force in Eqs.(16)-(17) participates to the equilibrium of single-degreeof-freedom oscillator (SDOF), representative of the RC frame dynamic response. The equilibrium of a lumped mass above the frame yields the following ordinary differential equation under earthquake excitation:

$$
m \ddot{x}+F_{T}=-m \ddot{x}_{g}
$$

where $m$ is the mass, $x$ the displacement, $\ddot{x}$ the double derivative of $x$ with respect to time, $F_{T}$ the resisting inelastic force defined in Eqs.(16)-(17), and $\ddot{x}_{g}$ the ground acceleration. A SDOF system is the most elementary structure. Nevertheless, it is the most meaningful, and the results obtained from this basic structure have universal application. The SDOF model is used to assess the slip force, which guarantees the lowest inter-storey drift. An RC frame represents any 
storey distinguished by a prevalent shear-type response. Accurately, any structure is a standalone case, but an elementary model's accurate analysis supports a mindful assessment of the optimum ranges to be expected in more complicated structures. In contrast with the previous section, the displacement is unknown and must descend from the numerical integration of the ODE. Precisely, the authors used the explicit fourth-order Runge-Kutta method for the temporal discretization of the approximate solution of the ODE. The optimization of the slip force in $\mathrm{AFC}$ descends from an indirect approach. The authors simulated the response of an RC frame equipped with the AFC to a set of 41 earthquakes by varying the value of the slip force in a given range. A list of 41 Italian earthquake records with magnitude $M_{L}$ ranging between 5 and 6.5 , reported in $[37,38]$, represented the base for generating 41 artificial earthquakes, scaled to the same PGA and optimized to match a given design spectrum. The design spectrum corresponds to the seismic scenario expected in L'Aquila, Italy, according to the National Seismic Code. The algorithm presented by [39] is used to scale the accelerograms to a 0.3PGA, and carry out the analyses based on coherent inputs. The algorithm modifies the frequency content without producing substantial shape modifications. The force slip varied in the range $0-100 \mathrm{kN}$, with a $1 \mathrm{kN}$ step. Fig.8 displays the results of the analyses. Fig.8(a) reports the maximum displacement drift due to a single earthquake. Maximum inter-story drift is widely used to evaluate the level of damage to both structural and non-structural elements in RC structures [32]. Fig.8(b) superposes the curves in Fig.8(a) by considering the responses to the 41 earthquakes. The mean and variance of the minima of the curves in Fig.8(b) leads to the normal distribution pictured in Fig.8(c).

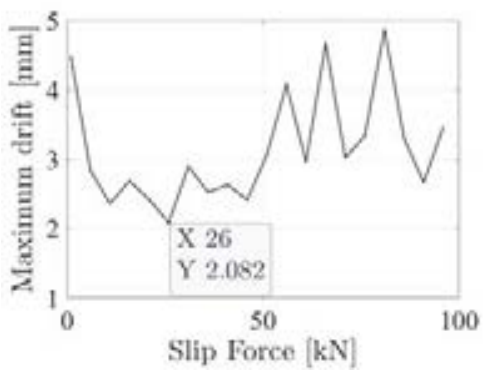

(a)

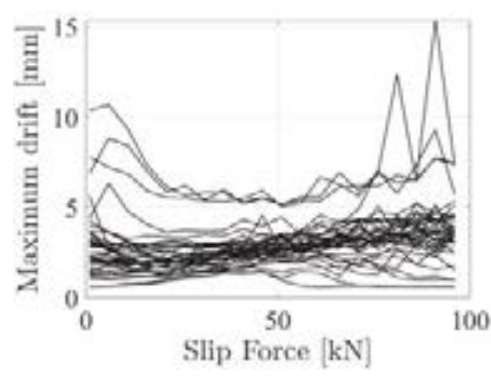

(b)

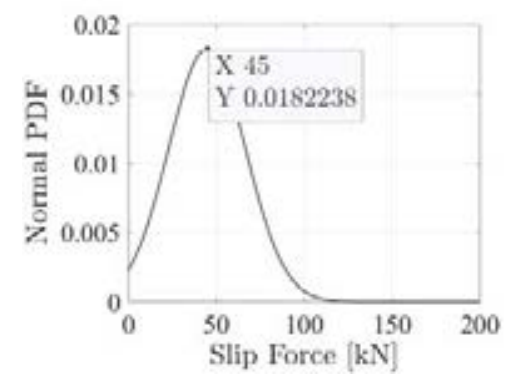

(c)

Figure 8: (a) Maximum drift of the RC frame from the response to the El Centro earthquake as a function of the slip force; (b) Superposition of the maximum drifts of the considered system under the earthquakes in Tab.??; (c) Half-Normal distribution of the slip force vales corresponding to the minimum drift.

The curves do not exhibit a smooth trend: they are very jagged. Still, despite the oscillation, each curve has a minima range with a concave shape by the minima. Hence, the authors picked the argument corresponding to the lowest value, considered representative of the optimum slip force. There are considerable differences between the curves obtained from different earthquakes. This evidence agrees with the findings by [16]. They observed that the optimum slip load values are more affected by the amplitude and frequency of the input earthquakes (e.g. peak ground acceleration) rather than the structure's characteristics.

Interestingly, the range of local minima gathers by the lower values of the slip force.

Also [29], [40] and [41] observed that the use of friction dampers leads to an optimum range of slip load ratios that, on average, leads to lower inter-story drifts. According to [29], the slip load ratio is the ratio between the slip value and the resistance of the structure without the 
passive device. They found the following empirical function for the prediction of the optimum slip force as a function of the number of storeys $n$ :

$$
R=1.12 e^{-0.11 n}
$$

If there is one storey, the $R$ ratio is almost one. As the number of storeys grows, the $R$ ratio reduces to 0.12 . This emirical equation does not agree with the outcomes of this investigation. The $R$ ratio in the considered configuration is $R \approx 0.23$.

According to [29], in the considered case, the optimum slip resistance should be approximately equal to $200 \mathrm{kN}$. Numerous factors are affecting the optimum value of the slip force. Both the $\mathrm{RC}$ frame and the AFC dissipate the seismic energy. The energy dissipated by the friction dampers is proportional to both the slip force and the mutual drift. If the slip force is kept low, the dissipated energy increment must descend from the increment in displacement. If the slip force is higher, a lower displacement can generate the same dissipation. However, higher forces cause the device activates when the RC frame has already experienced a significant displacement drift. In the considered system, characterized by strength and stiffness degradation, if the slip force was equal to $200 \mathrm{kN}$, the AFC's benefit was reduced by its tardy intervention.

Still, the RC frame with masonry infill can exhibit more the 50\% strength increment to the same structure without infill. If $R$ is the ratio between the slip resistance and the RC lateral capacity without the infill, the findings of this research and those by [29] become coherent, $R$ will approximate one. The masonry infill is determinant for the correct assessment of the optimum slip force.

\section{Conclusions}

The paper addresses the seismic performance of the e-CLT technology via nonlinear dynamic analysis on an elementary RC frame with masonry infill. The e-CLT technology is a seismic retrofitting solution of existing $\mathrm{RC}$ building based on the use of cross-laminated timber (CLT) panels and asymmetric friction connectors (AFC). In an RC frame, one end of the CLT panel is fixed on the lower beam, while the other end is equipped with an AFC, connected to the RC frame's upper beam. The slip force's exceeding in the AFC activates the dissipating device, which possibly contributes to the seismic energy absorption and the reduction of the displacement drift demand. The authors experimented the cyclic behaviour of the AFC and proposed a Coulomb-like model with a friction coefficient dependent on the dissipated hysteretic energy. The experimental data are used to simulate a frame's coupled response with masonry infill equipped with the AFC. The Atan model, which is an empirical hysteresis model proposed by [34], simulates the experimental cyclic response of an RC frame with masonry infill, tested by [31]. The authors tested the frame's response, represented by an SDOF oscillator with a lumped mass on the top, under a set of 41 earthquakes by varying the slip force in a given range. Interestingly, there is a range of minima where the slip force is associated with a significant reduction of the storey drift. The displacement reduction can be higher than 50\%. However, as observed by [16], seismic input's nature significantly affects the optimum slip force's value, which exhibits a significant scatter. The mean value of the optimum slip forces found in the considered structure is $45 \mathrm{kN}$, which is approximately the $21 \%$ of the shear resistance of the frame. This evidence does not match the findings by [29], who predicted higher optimum slip force values in bare RC structural archetypes with friction dampers; while in the analyses of this paper the $\mathrm{RC}$ frame was modelled with its real behaviour including the masonry infill. The masonry infill can add more than 50\% increment in strength and stiffness to the same RC frame without infill, in which case the results from this paper would align with [29]. 


\section{Funding}

This paper was carried out in the framework of the "Energy and seismic affordable renovation solutions" (e-SAFE) project, which has received funding from the European Union's Horizon 2020 research and innovation programme under grant agreement No.893135. Neither the Executive Agency for Small and Medium-sized Enterprises (EASME) nor the European Commission is in any way responsible for any use that may be made of the information it contains.

\section{REFERENCES}

[1] M. H. Milman and C.-C. Chu, "Optimization methods for passive damper placement and tuning," Journal of Guidance, Control, and Dynamics, vol. 17, no. 4, pp. 848-856, 1994.

[2] R. Levy and O. Lavan, "Fully stressed design of passive controllers in framed structures for seismic loadings," Structural and Multidisciplinary Optimization, vol. 32, no. 6, pp. 485498, 2006.

[3] I. Takewaki, Building control with passive dampers: optimal performance-based design for earthquakes. John Wiley \& Sons, 2011.

[4] S. Jaisee, F. Yue, and Y. H. Ooi, "A state-of-the-art review on passive friction dampers and their applications," Engineering Structures, vol. 235, p. 112022, 2021.

[5] S. Pagliaro, A. Aloisio, R. Alaggio, and A. Di Egidio, "Rigid block coupled with a 2 dof system: Numerical and experimental investigation," Coupled systems mechanics, vol. 9, no. 6 , pp. 539-562, 2020.

[6] A. Aloisio, L. D. Battista, R. Alaggio, E. Antonacci, and M. Fragiacomo, "Assessment of structural interventions using bayesian updating and subspace-based fault detection methods: the case study of s. maria di collemaggio basilica, l'aquila, italy," Structure and Infrastructure Engineering, pp. 1-15, 2020.

[7] A. Aloisio, I. Capanna, R. Cirella, R. Alaggio, F. Di Fabio, and M. Fragiacomo, "Identification and model update of the dynamic properties of the san silvestro belfry in l'aquila and estimation of bell's dynamic actions," Applied Sciences, vol. 10, no. 12, p. 4289, 2020.

[8] Y. Qie, F. Barbagallo, E. M. Marino, C. Du, and T. Wang, "Full-scale hybrid test for realistic verification of a seismic upgrading technique of rc frames by brbs," Earthquake Engineering \& Structural Dynamics, vol. 49, no. 14, pp. 1452-1472, 2020.

[9] A. S. Pall, C. Marsh, et al., "Response of friction damped braced frames," Journal of Structural Engineering, vol. 108, no. 9, pp. 1313-1323, 1982.

[10] M. Nakashima, K. Saburi, and B. Tsuji, "Energy input and dissipation behaviour of structures with hysteretic dampers," Earthquake engineering \& structural dynamics, vol. 25, no. 5, pp. 483-496, 1996.

[11] C.-G. Cho and M. Kwon, "Development and modeling of a frictional wall damper and its applications in reinforced concrete frame structures," Earthquake engineering \& structural dynamics, vol. 33, no. 7, pp. 821-838, 2004. 
[12] T. Fitzgerald, T. Anagnos, M. Goodson, and T. Zsutty, "Slotted bolted connections in aseismic design for concentrically braced connections," Earthquake spectra, vol. 5, no. 2, pp. 383-391, 1989.

[13] E. P. Popov, C. E. Grigorian, and T.-S. Yang, "Developments in seismic structural analysis and design,” Engineering structures, vol. 17, no. 3, pp. 187-197, 1995.

[14] C. E. Grigorian, T.-S. Yang, and E. P. Popov, "Slotted bolted connection energy dissipators," Earthquake Spectra, vol. 9, no. 3, pp. 491-504, 1993.

[15] G. Clifton, G. MacRae, H. Mackinven, S. Pampanin, and J. Butterworth, "Sliding hinge joints and subassemblies for steel moment frames," in Palmerston North, New Zealand: Proc of New Zealand Society for Earthq Eng Conf, 2007.

[16] A. Filiatrault and S. Cherry, "Seismic design spectra for friction-damped structures," Journal of Structural Engineering, vol. 116, no. 5, pp. 1334-1355, 1990.

[17] W. Y. Loo, C. Kun, P. Quenneville, and N. Chouw, "Experimental testing of a rocking timber shear wall with slip-friction connectors," Earthquake engineering \& structural dynamics, vol. 43, no. 11, pp. 1621-1639, 2014.

[18] A. Hashemi, P. Zarnani, R. Masoudnia, and P. Quenneville, "Experimental testing of rocking cross-laminated timber walls with resilient slip friction joints," Journal of Structural Engineering, vol. 144, no. 1, p. 04017180, 2018.

[19] A. Hashemi, H. Bagheri, S. M. M. Yousef-Beik, F. M. Darani, A. Valadbeigi, P. Zarnani, and P. Quenneville, "Enhanced seismic performance of timber structures using resilient connections: full-scale testing and design procedure," Journal of structural engineering, vol. 146, no. 9, p. 04020180, 2020.

[20] H. Mackinven, "Sliding hinge joint for steel moment frames experimental testing," Unpublished ENCI493 Project Report. Department of Civil Engineering, 2006.

[21] H.-H. Khoo, C. Clifton, J. Butterworth, G. MacRae, and G. Ferguson, "Influence of steel shim hardness on the sliding hinge joint performance," Journal of Constructional Steel Research, vol. 72, pp. 119-129, 2012.

[22] A. Sandoli, C. D’Ambra, C. Ceraldi, B. Calderoni, and A. Prota, "Sustainable crosslaminated timber structures in a seismic area: Overview and future trends," Applied Sciences, vol. 11, no. 5, p. 2078, 2021.

[23] A. Aloisio, D. Pasca, R. Tomasi, and M. Fragiacomo, "Dynamic identification and model updating of an eight-storey clt building," Engineering Structures, vol. 213, p. 110593, 2020.

[24] A. Aloisio and M. Fragiacomo, "Reliability-based overstrength factors of cross-laminated timber shear walls for seismic design," Engineering Structures, vol. 228, p. 111547, 2021.

[25] G. Margani, G. Evola, C. Tardo, and E. M. Marino, "Energy, seismic, and architectural renovation of rc framed buildings with prefabricated timber panels," Sustainability, vol. 12, no. 12 , p. $4845,2020$. 
[26] L. Moreschi and M. Singh, "Design of yielding metallic and friction dampers for optimal seismic performance," Earthquake engineering \& structural dynamics, vol. 32, no. 8, pp. 1291-1311, 2003.

[27] N. Nabid, I. Hajirasouliha, and M. Petkovski, "Performance-based optimisation of rc frames with friction wall dampers using a low-cost optimisation method," Bulletin of Earthquake Engineering, vol. 16, no. 10, pp. 5017-5040, 2018.

[28] L. F. F. Miguel, L. F. F. Miguel, and R. H. Lopez, "Simultaneous optimization of force and placement of friction dampers under seismic loading," Engineering Optimization, vol. 48, no. 4, pp. 582-602, 2016.

[29] N. Nabid, I. Hajirasouliha, and M. Petkovski, "A practical method for optimum seismic design of friction wall dampers," Earthquake Spectra, vol. 33, no. 3, pp. 1033-1052, 2017.

[30] J. C. Golondrino, G. MacRae, and C. Clifton, "Behaviour of asymmetrical friction connections using different shim materials," in Proceedings of the New Zealand Society for Earthquake Engineering Conference, 2012.

[31] L. Cavaleri and F. Di Trapani, "Cyclic response of masonry infilled rc frames: Experimental results and simplified modeling," Soil Dynamics and Earthquake Engineering, vol. 65, pp. 224-242, 2014.

[32] I. Hajirasouliha, P. Asadi, and K. Pilakoutas, "An efficient performance-based seismic design method for reinforced concrete frames," Earthquake engineering \& structural dynamics, vol. 41, no. 4, pp. 663-679, 2012.

[33] C. Tardo, F. Boggian, M. Hatletveit, E. Marino, G. Margani, and R. Tomasi, "Mechanical characterization of energy dissipation devices in retrofit solution of reinforced concrete frames coupled with solid wood panels," in Proceedings of the 12th International Conference on Structural Analysis of Historical Constructions, 2020.

[34] A. Aloisio, P. Sejkot, A. Iqbal, and M. Fragiacomo, "An empirical transcendental hysteresis model for structural systems with pinching and degradation," Earthquake Engineering \& Structural Dynamics.

[35] G. C. Foliente, "Hysteresis modeling of wood joints and structural systems," Journal of Structural Engineering, vol. 121, no. 6, pp. 1013-1022, 1995.

[36] A. Aloisio, R. Alaggio, J. Köhler, and M. Fragiacomo, "Extension of generalized boucwen hysteresis modeling of wood joints and structural systems," Journal of Engineering Mechanics, vol. 146, no. 3, p. 04020001, 2020.

[37] A. Aloisio, R. Alaggio, and M. Fragiacomo, "Fragility functions and behavior factors estimation of multi-story cross-laminated timber structures characterized by an energydependent hysteretic model," Earthquake Spectra, p. 8755293020936696, 2020.

[38] A. Aloisio, R. Alaggio, and M. Fragiacomo, "Equivalent viscous damping of crosslaminated timber structural archetypes," Journal of Structural Engineering, vol. 147, no. 4, p. $04021012,2021$. 
[39] F. Ferreira, C. Moutinho, Á. Cunha, and E. Caetano, "An artificial accelerogram generator code written in matlab," Engineering Reports, vol. 2, no. 3, p. e12129, 2020.

[40] M. Petkovski and P. Waldron, "Optimum friction forces for passive control of the seismic response of multi-storey buildings," Proc. of the 40 years of European Earthquake Engineering SE4OEEE, 2003.

[41] N. Fallah and S. Honarparast, "Nsga-ii based multi-objective optimization in design of pall friction dampers," Journal of Constructional Steel Research, vol. 89, pp. 75-85, 2013. 